\title{
Genome-wide analysis of rice ClpB/HSP100, ClpC and ClpD genes
}

Amanjot Singh, Upasana Singh, Dheeraj Mittal, Anil Grover*

\begin{abstract}
Background: ClpB-cyt/HSP100 protein acts as chaperone, mediating disaggregation of denatured proteins. Previous studies have shown that ClpB-cyt/HSP100 gene belongs to the group class I Clp ATPase proteins and ClpB-cyt/HSP100 transcript is regulated by heat stress and developmental cues.

Results: Nine ORFs were noted to constitute rice class I Clp ATPases in the following manner: 3 ClpB proteins (ClpB-cyt, Os05g44340; ClpB-m, Os02g08490; ClpB-c, Os03g31300), 4 ClpC proteins (ClpC1, Os04g32560; ClpC2, Os12g12580; ClpC3, Os11g16590; ClpC4, Os11g16770) and 2 ClpD proteins (ClpD1, Os02g32520; ClpD2, Os04g33210). Using the respective signal sequences cloned upstream to GFP/CFP reporter proteins and transient expression studies with onion epidermal cells, evidence is provided that rice ClpB-m and Clp-c proteins are indeed localized to their respective cell locations mitochondria and chloroplasts, respectively. Associated with their diverse cell locations, domain structures of OsClpB-c, OsClpB-m and OsClpB-cyt proteins are noted to possess a high-level conservation. OsClpB-cyt transcript is shown to be enriched at milk and dough stages of seed development. While expression of OsClpB-m was significantly less as compared to its cytoplasmic and chloroplastic counterparts in different tissues, this transcript showed highest heat-induced expression amongst the $3 \mathrm{ClpB}$ proteins. OsClpC1 and OsClpC2 are predicted to be chloroplast-localized as is the case with all known plant ClpC proteins. However, the fact that OsClpC3 protein appears mitochondrial/chloroplastic with equal probability and OsClpC4 a plasma membrane protein reflects functional diversity of this class. Different class I Clp ATPase transcripts were noted to be cross-induced by a host of different abiotic stress conditions. Complementation assays of $\Delta$ hsp 104 mutant yeast cells showed that OsClpB-cyt, OsClpB-m, OsClpC1 and OsClpD1 have significantly positive effects. Remarkably, OsClpD1 gene imparted appreciably high level tolerance to the mutant yeast cells.

Conclusions: Rice class I Clp ATPase gene family is constituted of 9 members. Of these 9, only 3 belonging to ClpB group are heat stress regulated. Distribution of ClpB proteins to different cell organelles indicates that their functioning might be critical in different cell locations. From the complementation assays, OsClpD1 appears to be more effective than OsClpB-cyt protein in rescuing the thermosensitive defect of the yeast ScAhsp104 mutant cells.
\end{abstract}

\section{Background}

Heat stress threatens future prospects of increased grain production in crops. Rice (Oryza sativa) is most important world food crop. The production of rice is getting severely affected with increases in mean global temperature. According to estimates, yield of rice declines by $10 \%$ for every $1^{\circ} \mathrm{C}$ increase in growing period minimum temperature in the dry season [1]. Processes like spikelet fertility, grain quality and yield processes in rice are considered to be especially sensitive to heat stress [2]. For

\footnotetext{
*Correspondence: anil.anilgrover@gmail.com

Department of Plant Molecular Biology, University of Delhi South Campus, New Delhi-110021, India
}

breeding heat tolerant rice, it is important that molecular components that underlie the heat shock response in this species are understood [3]. Microarray profiling data have shown that heat stress response in maturing tomato microspores involves heat shock proteins, ROS scavengers, hormones and sugars [4]. Understandably, the major molecular changes in rice plants as affected by heat stress need to be worked out. This is especially relevant since rice has emerged as a model plant species of the group monocots due to its small genome size, availability of large collection of full-length cDNAs (FLcDNAs) and for the fact that the whole genome of this plant species is completely sequenced. This crop has 
attracted a great deal of efforts for the elucidation of gene functions; completion of genome sequencing in rice has paved way for comprehensive functional characterization of genes, transcription factors, signaling components and promoters [5,6]. The completed rice genome sequence has been used for the characterization of a large number of gene families involved in diverse processes and pathways. However, with almost 42000 genes [7], several of them unknown, there are ample proteins still left to be characterized in this important crop species. In recent years, comprehensive details on heat shock regulated rice HSP20, HSP70, HSP90 and HSF gene families have been reported [8-11]. HSP100 is a major heat-regulated protein family in diverse organisms. Across the living systems, common features of HSP100 chaperone action include transient interactions with non-native protein species, in the prevention of aggregation and promotion of correct folding and assembly, or in unfolding for translocation or targeting to proteases. Singla and Grover [12] showed that homologues of yeast HSP104 protein are expressed in heat shocked rice seedlings. It was subsequently established that apart from heat, rice HSP100 expression is developmentally-controlled as seeds and developing embryos of rice show high constitutive levels of this protein $[13,14]$.

HSP100 proteins belong to ClpB family [15-17]. Clp ATPases maintain quality of cellular proteins by performing the function of molecular chaperones and energy dependent proteases. Clp (Caseinolytic Protease) system was first identified as a heat shock inducible, multicomponent, ATP-dependent protease complex able to hydrolyze casein $[18,19]$. Subsequent studies showed that the Clp system can hydrolyze numerous other proteins and peptides in both aggregated and non-aggregated forms [20] Clp ATPases fall within the AAA ${ }^{+}$ superfamily of ATPases associated with a substantially broader range of biological processes [21,22]. Class I ATPases (ClpA, ClpB, ClpC, ClpD) have two ATP binding domains and class II Clp ATPases (ClpM, ClpN, ClpX, ClpY) have one ATP binding domain [23]. Clp proteins are localized in various cellular organelles in plants [24]. Basically, Clp system members include three non-homologous gene families: ClpABCXY, ClpP and ClpQ. ClpACX members (but not ClpB) facilitate the activity of ClpP and some, such as ClpA [25] and ClpX [26], can function as independent chaperones in roles analogous to those of DnaK and DnaJ proteins. In contrast, ClpP proteolytic subunit exhibits low levels of peptidolytic activity. Further, when ClpP is complexed with ClpA, ClpC or ClpX, active holoenzymes which are able to cleave denatured proteins are formed. ClpAP, ClpXP and HslUV proteases are similar in design to the eukaryotic $26 \mathrm{~S}$ proteasome, with the ATPase subunits guarding the entrance to the proteolytic chamber $[27,28]$. Clp proteases in bacterial and eukaryotic systems have been implicated in vital cellular processes such as sporulation, DNA replication, protein turnover, stress tolerance and acclimation and regulation of gene expression [29]. ClpB is different from ClpA, ClpX and HslU as it does not associate with peptidase subunits. The function of $\mathrm{ClpB}$ is also distinct from that of other Clp ATPases: this protein is not involved in protein degradation [30], instead it disaggregates and reactivates strongly aggregated proteins [31-33]. The aggregation reversing activity of ClpB requires cooperation with the HSP70/HSP110 chaperone machinery [34].

In Arabidopsis, ClpB proteins have been divided into 3 classes according to cytoplasmic, chloroplastic and mitochondrial isoforms. Cytoplasmic $\mathrm{ClpB}$ is constituted by At1g74310, chloroplastic ClpB by At5g15450 and mitochondrial ClpB by At2g25140 [17]. Much of the work on ClpB proteins has been carried out on AtClpB-cyt isoform [35-38]. We isolated and sequenced rice ClpBcyt gene (GenBank accession no. AJ316025) and showed that rice ClpB-cyt cDNA complements yeast hsp104 deletion and loss of thermotolerance trait in yeast [39]. Genetic analysis has shown that ClpB-cyt protein is essential for heat tolerance in plants. Mutants of Zea mays and $A$. thaliana plants under-expressing their respective $\mathrm{ClpB}$-cyt/HSP100 proteins are observed to lack both basal as well as induced thermotolerance [35-37]. Queitsch et al [38] produced transgenic $A$. thaliana plants by modifying level of AtClpB-cyt/ HSP100 protein. Transgenic plants in the latter study survived as high as $45^{\circ} \mathrm{C}(1 \mathrm{~h})$ temperature stress as they showed vigorous growth after the removal of stress. Katiyar-Agarwal et al [40] over-expressed AtClpB-cyt/ HSP100 protein in rice plants. The transgenic rice lines showed re-growth in the post-high temperature stress recovery phase while the untransformed plants could not recover to the similar extents. Keeler et al [41] reported cloning of a chloroplastic $H S P 100 / C l p B$ gene from Phaseolus lunatus. The corresponding protein was seen to be localized to chloroplast. The accumulation of ClpB/HSP100 in this plant species was tightly correlated with heat acclimation, suggesting that the chloroplastic ClpB/HSP100 may be an important protein for acquiring thermotolerance. Chloroplastic ClpB from Lycopersicon esculentum has been shown to be important in acquired thermotolerance [42]. Antisense suppression of LeHSP100/ClpB in tomato plants made the plants more heat sensitive. Lee et al [17] noted that Arabidopsis knockout $C l p B-p$ plants turn yellow on heat treatment. $C l p B-p$ mutant plants showed a distinct change in chloroplast morphology upon subjecting plants to high temperature stress: chloroplasts were irregular to roundish in shape and were $21.5 \%$ of the size of normal chloroplasts. Lee et al [17] reported that At2g25140 (ClpB-m) 
was localized to mitochondria based on experiments in which transgenic Arabidopsis plants produced with signal peptide of At2g25140 fused with GFP showed expression of the reporter gene in mitochondria. This group further noted that the $C l p B-m$ transcript was upregulated during heat shock and the level of induced transcript for $C l p B-m$ was lower as compared to AtHSP100 and ClpB-p transcripts. ClpB-m knockout Arabidopsis plants grew in comparable way to the wild type plants both during induced and acquired thermotolerance.

Plant ClpC proteins, which are the homolog of the $E$. coli ClpA proteins, have been noted in chloroplast stroma of several plant species [43-45]. ClpCs are considered to be highly conserved proteins among different species [46]. ClpC of Bacillus subtilis has been found not only to be involved in the removal of misfolded and aggregated proteins but also controls through regulated proteolysis, several key steps of development [47]. Two nearly-identical ClpC isomers exist in Arabidopsis. ClpC has been seen to be associated with $\mathrm{ClpP}$ in the stroma [48,49] in an ATP dependent manner [50]. Sjogren et al [51] reported that clpC1 mutant Arabidopsis plants display a retarded growth phenotype and leaves with a homogeneous chlorotic appearance. This mutant also exhibited fewer photosystem I and photosystem II complexes. ClpC in Synechococcus elongatus has been noted to possess ATPase activity as well as function as a molecular chaperone without the need of additional chaperones or adaptor proteins [52]. It is suggested that ClpC functions in part as a housekeeping chaperone in vivo, protecting unfolded, newly synthesized (or recently imported as in chloroplasts) polypeptides from aggregation. ClpD proteins differ from $\mathrm{ClpCs}$ by specific signature sequence and by its differential expression characteristics $[23,44]$. ClpD in Arabidopsis has previously been referred to as ERD1 [44,53,54] and SAG15 [55]. Weaver et al [56] reported that the ERD1 protein declines while its mRNA increases during senescence in Arabidopsis.

It is hence clear that plant Clps are associated with stress and developmental processes. The comprehensive analysis of rice Clp ATPases with respect to their structural and functional aspects has not been addressed to as yet. This study provides information on rice class I Clp ATPases with respect to genomic organization, regulation, protein architecture and cellular functions.

\section{Results}

\section{Genome complexity of rice class I Clp ATPase members}

The protein sequence of rice ClpB/HSP100 (accession number AJ316025) was noted to be same as the protein encoded by the MSU locus Os05g44340. Os05g44340 was used as a query for identifying the other $\mathrm{Clp}$ homologs at the MSU rice database. Nine ORFs encoded by Os02g08490, Os02g19450, Os02g32520, Os03g31300, Os04g32560, Os04g33210, Os11g16590, Os11g16770 and Os12g12850 loci were noted to share homology to Os05g44340 in this analysis (Table 1). Search using HSP100 as a key word showed that Os08g15230 is also one of the probable candidate genes belonging to Clp ATPase family. However, alignment of protein sequence of Os08g15230 with Os05g44340 showed that Os08g15230 does not contain most of the domains which are typically present in Clp proteins (except for the truncated ClpN domain). Therefore, Os08g15230 is not included as Clp ATPase family member herein. Further, Os02g19450 locus encoding for a mitochondrial 74kDa protein (HSP74) showed high similarity to yeast HSP78 protein. Though Os02g19450 protein appeared to be the closest homologue of Os05g44340 protein in terms of sequence similarity (59\%), Os02g19450 lacked the N-terminal domain which other mitochondrial HSP78 proteins possess. Importantly, Os02g19450 locus appears not to be expressed in rice based on microarray as well as Quantitative-PCR (Q-PCR) analysis while the yeast HSP78 protein is strongly expressed in response to high temperature stress. We have therefore omitted Os02g19450 gene as well from the class I Clp ATPase family in further discussion. Overall then, we assume that 9 ORFs (i.e. Os02g08490, Os02g32520, Os03g31300, Os04g32560, Os04g33210, Os05g44340, Os11g16590, Os11g16770 and Os12g12850; Table 1) constitute rice class I Clp ATPases.

\section{Phylogenetic relationship among plant class I Clp ATPases}

Phylogenetic analysis of rice class I Clp ATPases with the corresponding Arabidopsis proteins (6 ORFs, details shown in Additional file 1) enabled us to annotate and classify the above 9 rice ORFs into ClpB, C and D classes as follows: $3 \mathrm{ClpB}$ proteins (designated as B1, Os05g44340; B2, Os02g08490; B3, Os03g31300), 4 ClpC proteins (C1, Os04g32560; C2, Os12g12580; C3, Os11g16590; C4, Os1g16770) and 2 ClpD proteins (D1, Os02g32520; D2, Os04g33210). The extent of identity of these proteins with respect to Os05g44340 is as follows: Os02g08490-54.8\%, Os02g32520-28.3\%, Os03g3130050.8\%, Os04g32560-40\%, Os04g33210-26.2\%, Os11g16590-40.9\%, Os11g16770-49.4\% and Os12g12580-29.1\%. Populus trichocarpa is the first tree species whose genome has been sequenced. A BLASTP search of Populus genome at http://genome.jgi-psf.org/ Poptr1_1/ revealed that it has 8 homologs to rice Os05g44340. Clp ATPases from Populus have been named in this text as per the system described by Waters et al [57] for LMW HSPs. Molecular details for the 8 Populus Clp ATPases are shown in Additional file 
Table 1 Properties of rice class I Clp ATPase members. aa- amino acids; pl- isoelectric point.

\begin{tabular}{llllll}
\hline Locus & $\begin{array}{l}\text { Suggested } \\
\text { nomenclature }\end{array}$ & $\begin{array}{l}\text { Mol. Wt. (kDa), Length (aa), } \\
\text { pl }\end{array}$ & $\begin{array}{l}\text { Signal peptide } \\
(\mathbf{a a})\end{array}$ & $\begin{array}{l}\text { Predicted cellular } \\
\text { localization }\end{array}$ & $\begin{array}{l}\text { Gene length, ORF, } \\
\text { introns }\end{array}$ \\
\hline Os02g08490 & ClpB-M & $116.04,1043,7.26$ & 87 & Mitochondria & $5072,2952,9$ \\
Os02g32520 & ClpD1 & $101.8,938,7.02$ & 83 & Chloroplast & $4465,2817,11$ \\
Os03g31300 & ClpB-C & $108.9,978,6.44$ & 76 & Chloroplast & $6378,2937,14$ \\
Os04g32560 & ClpC1 & $101.8,918,6.32$ & 28 & Chloroplast & $5309,2757,8$ \\
Os04g33210 ClpD2 & $93.2,858,8.38$ & 80 & Chloroplast & $5183,2577,9$ \\
Os05g44340 & ClpB-Cyt & $100.8,912,6.07$ & None & Cytoplasm/Nucleus & $3106,2739,4$ \\
Os11g16590 ClpC3 & $100.8,932,8.24$ & 48 & Chloroplast/Mitochondria & $5001,2799,8$ \\
Os11g16770 & ClpC4 & $100.9,918,9.46$ & 21 & Plasma Membrane & $5299,2757,8$ \\
Os12g12850 ClpC2 & $102.01,919,6.89$ & 54 & Mitochondria & $4729,2760,8$ \\
\hline
\end{tabular}

1. Overall, we find that Populus genome contains $4 \mathrm{ClpB}$ (Pt101.7, Pt106.7, Pt108.5 and Pt98.7), 2 ClpC (Pt102.5 and Pt103.5) and $2 \mathrm{ClpD}$ (Pt103.2 and Pt104.4) genes. Arabidopsis-rice-Populus phylogenetic tree was constructed using amino acid sequences of 9 Clp ATPase proteins from rice (sequences downloaded from MSU rice database), 6 from Arabidopsis (sequences downloaded from MIPS database) and 8 from Populus (sequences downloaded from http://genome.jgi-psf.org/ Poptr1_1/Poptr1_1.home.html using ClustalX and visualized using Treeview (Figure 1). The tree divided all 23 proteins into 3 major clades corresponding to ClpB, $\mathrm{ClpC}$ and $\mathrm{ClpD}$ proteins. ClpB clade was divided into 3 subclades according to cytoplasmic, chloroplastic and mitochondrial isoforms. Cytoplasmic ClpB are Os05g44340, At1g74310 and Pt101.72; chloroplastic ClpB are Os03g31300, At5g15450, Pt106.69 and Pt108.53 and mitochondrial $\mathrm{ClpB}$ are Os02g08490, At2g25140 and Pt98.74. At the amino acid level, Os02g08490 is $82.5 \%$ similar to At2g25140 which has recently been reclassified from AtClpB4 to AtClpB-M [17]. Os03g31300 showed high similarity (84\%) with At5g15450. Os05g 44340 has a similarity of $83.4 \%$ with At1g74310 at the amino acid level. ClpC clade contained 4 rice (Os04g32560, Os12g12850, Os11g16770 and Os11g16590), 2 Arabidopsis (At3g48870 and At5g50920) and 2 Populus (Pt102.5 and Pt103.51) members. At the amino acid level, Os04g32560 (OsClpC1) shows homology of 82.3 and $87.5 \%$ with At3g48870 and At5g50920, respectively. Os12g12850 (OsClpC2) shares $87.6 \%$ similarity with Os04g32560, the sequence being dissimilar only in the region towards $\mathrm{N}$-terminus which corresponds to the signal peptide. Os12g12850 shows $83 \%$ and $86.5 \%$ identity at the amino acid levels with At3g48870 and At5g50920, respectively. Pt102.5 and Pt103.51 showed similarity in the range of $84-86 \%$ to Os04g32560 and Os12g12850, suggesting that ClpC ATPases are highly conserved across phyla. Os11g16770 and Os11g16590 also appear to be members of ClpC clade. ClpD class included two proteins from rice (Os02g32520 and Os04g33210), one from Arabidopsis
(At5g51070) and two from Populus (Pt103.2 and Pt104.39). Os02g32520 has identity of $62.8 \%$ with At5g51070 which was previously identified as ERD1 protein and later rechristened as AtClpD [17]. Os04g33210 shows $60 \%$ sequence identity to At5g51070 at the amino acid level. Pt103.2 and Pt104.39 showed similarity ranging from $61-65 \%$ at the amino acid level with their rice counterparts. Table 1 provides detailed properties of rice class I Clp ATPase genes.

\section{Genomic organization of rice class I Clp ATPase genes}

Rice class I Clp ATPase genes appear to be distributed in the genome (Table 1). There is no duplication event seen in these genes, suggesting that these genes have evolved independently from each other and there is no transposition involved. However, the evolutionary patterns of organellar and cytoplasmic isoforms of various class I Clp ATPases remain to be analyzed. Further, there is not much similarity among these genes at the level of distribution of exon and intron sequences: all class I Clp ATPase genes contained introns and there was no specific pattern in the arrangement of exons and introns in their genomic loci (Additional file 2). $O s C l p B-c$ has 15 exons and 14 introns which accounts for the most in any Clp member in rice class I ATPase gene family. OsClpB-cyt appears the smallest gene among rice class I Clp ATPase genes with respect to the genic region occupied. With respect to the proposed ORF of $O s C l p C 1$ gene, a discrepancy was noted: KOME database shows AK058510 to contain ORF of $1.107 \mathrm{~kb}$ while MSU database predicts ORF of $2.757 \mathrm{~kb}$. While $2.757 \mathrm{~kb}$ ORF seems to encode the complete protein (918 amino acids; $101.8 \mathrm{kDa}$ protein), there are no databank entries corresponding to $2.757 \mathrm{~kb}$ transcript of this gene. KOME clone in fact contains the last 1.211 $\mathrm{kb}$ region of the $2.757 \mathrm{~kb}$ clone. In this study, full length $\mathrm{OsClpC1}$ was cloned from control unstressed rice seedling tissues using RT-PCR. Since a band corresponding to $\sim 2.7 \mathrm{~kb}$ on $1 \%$ agarose gel in this reaction was noted (data not shown), it is thus indicated that OsClpC1 ORF is $\sim 2.7 \mathrm{~kb}$ under the conditions examined herein. 


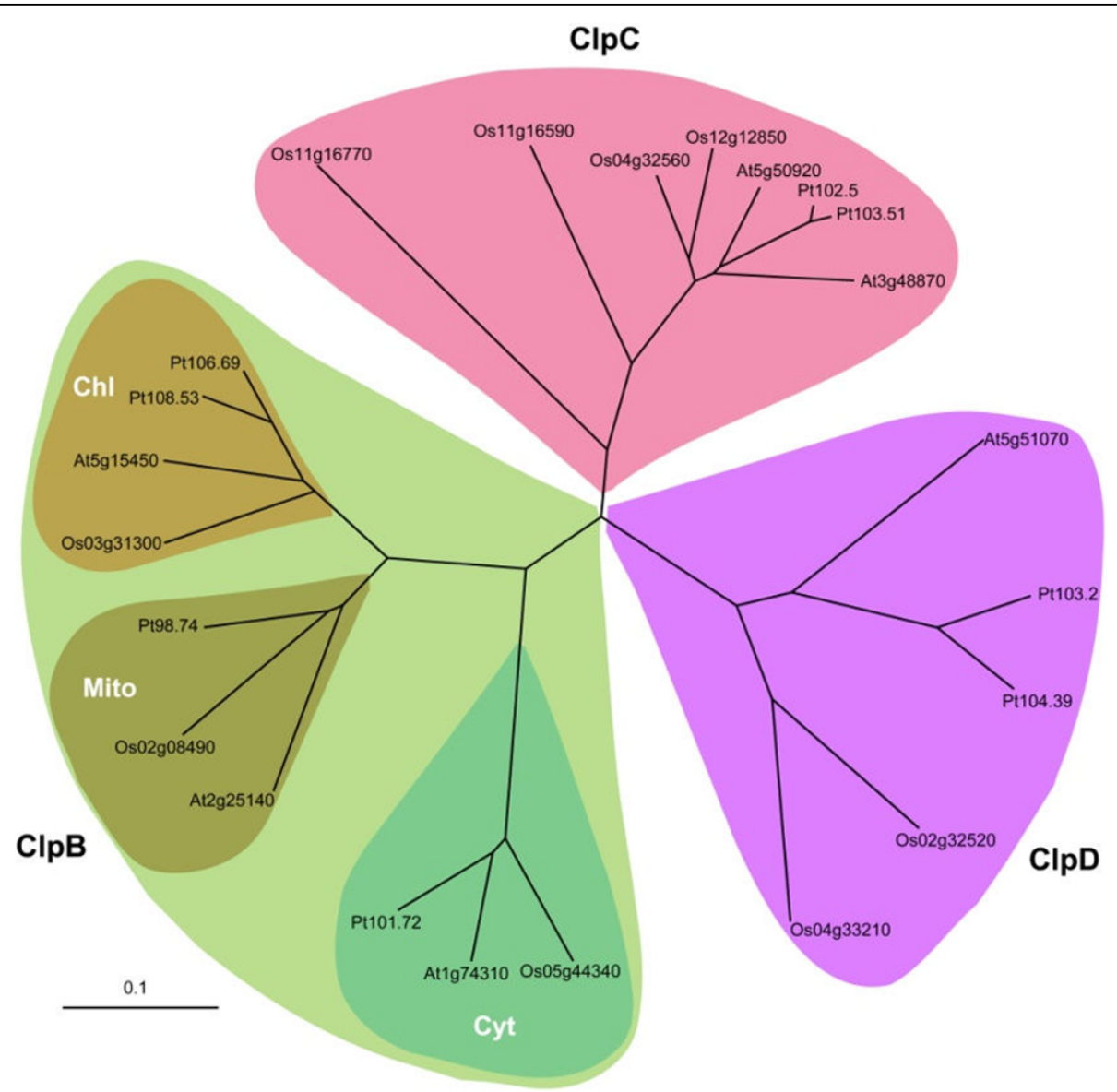

Figure 1 Phylogenetic relatedness among different class I Clp ATPase proteins from rice, Arabidopsis and Populus. The phylogenetic tree was created using ClustalX 1.83, based on the predicted amino acid sequences. The branch lengths are proportional to divergence, with the scale of 0.1 representing $10 \%$ change.

\section{Domain structure of class I OsClp ATPase proteins}

SMART and PFAM database were analyzed for retrieving information on various domains present in rice class I Clp ATPase proteins. In OsClpB-cyt, NBD1 and NBD2 span amino acids 209-398 and 607-710, respectively (Figure 2A). OsClpB-cyt also contains a spacer region which spans 494-553 amino acids; this spacer is characteristic of ClpB proteins. M-domain overlaps with spacer signature II. The signal peptides were predicted using Predotar and LOCTREE programs. Os02g08490 was predicted to be mitochondrial (hence shown as OsClpBm), while Os03g31300 was predicted to be chloroplastic (hence shown as OsClpB-c). Although OsClpB-cyt is considered to be cytoplasmic, its amino acid sequence analyzed at LOCTREE program predicts that this protein is nuclear-localized and contains a putative nuclear localization signal (NLS) present from amino acid 476 to 483 (RKLKQREE). The architecture and the physical position of various domains in $\mathrm{ClpC}$ and $\mathrm{ClpD}$ proteins are shown in Figure 3. It is amply clear from this analysis that rice Clp $\mathrm{C}$ and $\mathrm{D}$ proteins belong to class $\mathrm{I}$ ATPases, containing two NBDs (Figure 3B). All the class I Clp ATPase proteins except OsClpC4 were seen to contain two copies of ClpN domain (Additional file 3). This domain present towards the N-termini is speculated to have a role in protein binding. $\mathrm{ClpC} 2, \mathrm{C} 3, \mathrm{C} 4$ and D2 proteins contained 35 amino acids long UVR domain between the two NBDs. UVR domains have been seen in proteins which have role in DNA recognition, repair and processing. The proteins containing UVR domain are reportedly able to interact with each other through this domain. OsClpC1 and OsClpC2 are predicted to be chloroplast-localized. On the other hand, $\mathrm{ClpC} 3$ is predicted to be mitochondrial/chloroplastic with equal probability and $\mathrm{OsClpC4}$ is predicted to be present in plasma membrane. All the ClpC 
A.

\begin{tabular}{|llll|}
\hline Domain & OsClpB-m & OsClpB-c & OsClpB-cyt \\
\hline Signal peptide & $1-87$ & $1-76$ & None \\
NBD1 Walker A & $300-307$ & $289-296$ & $209-216$ \\
Channel loop 1 & $337-343$ & $326-340$ & $246-260$ \\
NBD1 B1 & $358-373$ & $347-361$ & $267-281$ \\
Sensor motif 1 & $403-412$ & $392-401$ & $312-321$ \\
NBD1 B2 & $478-489$ & $467-478$ & $387-398$ \\
ClpB Unique sequence & $502-536$ & $491-511$ & $411-445$ \\
Spacer signature II & $585-598$ & $574-587$ & $494-510$ \\
Spacer signature III & $639-649$ & $628-638$ & $544-553$ \\
NBD2 Walker A & $703-710$ & $692-699$ & $607-614$ \\
Channel loop 2 & $746-757$ & $735-746$ & $650-661$ \\
NBD2 Walker B & $795-805$ & $784-794$ & $700-710$ \\
C-terminal signature IV & $853-870$ & $841-858$ & $752-769$ \\
C-terminal signature V & $917-925$ & $905-913$ & $816-824$ \\
\hline
\end{tabular}

B.

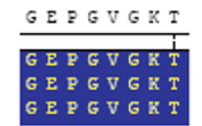

NBD1 Walker $A$

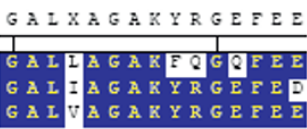

Channel loop 1

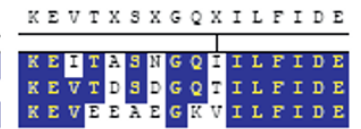

NBD1 Walker B1

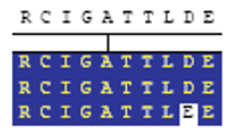

Sensor motif 1

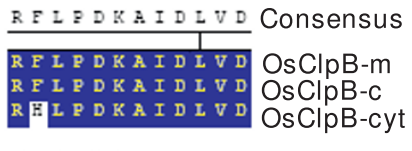

NBD1 Walker B2

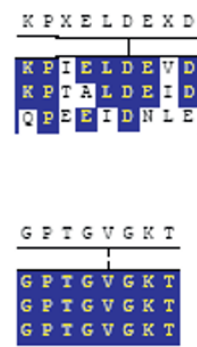

NBD2 Walker A
ClpB unique sequence

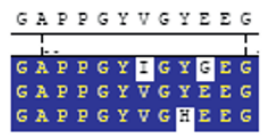

Channel loop 2

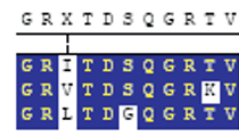

NBD2 Walker B

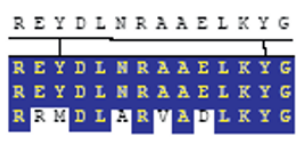

Spacer signature II

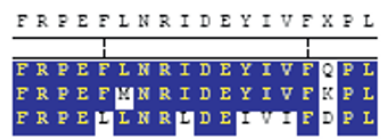

C-terminal Signature IV

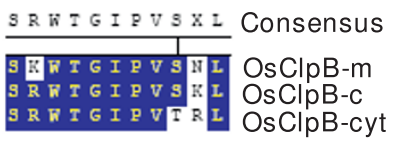

Spacer signature III

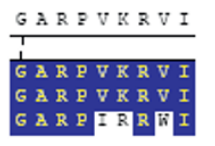

Consensus

OsClpB-m OsClpB-c OsClpB-cyt

C-terminal

Signature V

Figure 2 A. Relative positions of different domains present in rice class I ClpB proteins. The position of amino acids was marked manually after aligning the sequences in MegAlign module of DNASTAR. B. Consensus sequence of the different domains present in rice class I ClpB proteins. Alignments were done using ClustalV of MegAlign module of DNASTAR and alignment pictures were modified for representation.

proteins identified to date in Arabidopsis and Populus are localized in the chloroplast where they interact with the chloroplastic protease ClpP.

Furthermore, 3-dimensional structures of OsClpBs were predicted using I-TASSER [58]. Of the various models suggested, structures which had a higher Cscore were taken ( $\mathrm{C}$-score considered to be a confidence score for estimating the quality of predicted models by I-TASSER). Importantly, OsClpB-c, OsClpB-m and OsClpB-cyt showed almost similar structural arrangements as has been seen in case of A. thaliana ClpB (Additional file 4). The coiled-coil linker formed the central portion of the structures and the two NBDs flanked it. The predicted binding sites also showed the same pattern in the three $\mathrm{ClpB}$ isoforms (Additional file 5). From the structures proposed, it is suggested that OsClpB-c, OsClpB-m and OsClpB-cyt proteins are remarkably conserved with respect to their predicted protein binding sites.

In E. coli, complex formation between ClpA and ClpX with ClpP is mediated by a helix-loop-helix motif in which the tip of the loop contains an essential IGF/L tripeptide [59]. In case of rice Clp ATPase proteins, it was seen that except OsClpB-m, OsClpB-c and OsClpB-cyt (ClpB members), all other Clp class I ATPase proteins contain this tripeptide IGF/L motif (Figures 2,3). This 
A.

\begin{tabular}{|lllllll|}
\hline Domain & OsClpC1 & OsClpC2 & OsClpC3 & OsClpC4 & OsClpD1 & OsClpD2 \\
\hline Signal peptide & $1-80$ & $1-54$ & $1-48$ & $1-21$ & $1-83$ & $1-28$ \\
NBD1 Walker A & $296-303$ & $297-304$ & $309-316$ & $311-318$ & $311-318$ & $296-303$ \\
Channel loop 1 & $333-347$ & $334-348$ & $346-360$ & $348-362$ & $348-361$ & $333-347$ \\
NBD1 B1 & $352-368$ & $353-369$ & $365-381$ & $367-383$ & $368-383$ & $352-368$ \\
Sensor motif 1 & $398-408$ & $399-408$ & $411-420$ & $413-422$ & $417-425$ & $398-407$ \\
NDB1 B2 & $473-485$ & $474-486$ & $486-498$ & $488-500$ & $492-503$ & $473-484$ \\
Spacer signature II & Absent & Absent & Absent & Absent & Absent & Absent \\
Spacer signature III & $575-587$ & $576-588$ & $589-601$ & $589-601$ & $596-607$ & $575-586$ \\
NBD2 Walker A & $639-647$ & $640-648$ & $653-661$ & $653-661$ & $660-668$ & $639-647$ \\
Channel loop 2 & $682-693$ & $683-694$ & $696-707$ & $700-711$ & $703-714$ & $682-693$ \\
NBD2 Walker B & $738-746$ & $739-747$ & $752-760$ & $756-764$ & $759-767$ & $738-746$ \\
C-Terminal signature IV & $791-811$ & $794-812$ & $806-824$ & $803-820$ & $813-887$ & $793-811$ \\
C-terminal signature V & $858-867$ & $859-868$ & $871-880$ & $867-878$ & $878-887$ & $858-867$ \\
ClpP interacting motif & $687-689$ & $767-769$ & $849-851$ & $169-171$ & $856-858$ & $766-768$ \\
& (IGF) & (IGF) & (IGL) & (IGL) & (IGL) & (IGF) \\
\hline
\end{tabular}

B.

GEPGVGKT GLLVAGTKYRGE MEEVKOAGDIILFIDE QCIGATTLDE RFLPDKAIDSSWTGIPVEK CONSENSUS
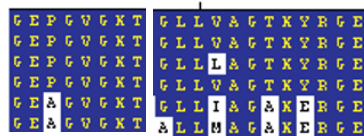

NBD1 Walker A

Channel loop 1

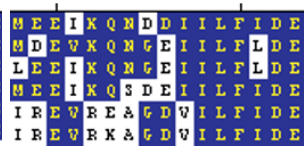

NBD1 Walker B1

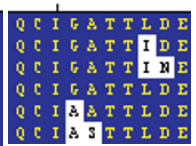

Sensor motif 1

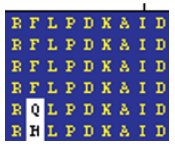

NBD Walker B2 Spacer Signature III

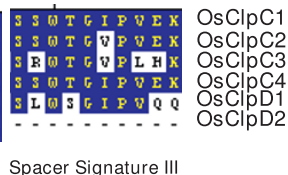

A R P R R A COM Consensus

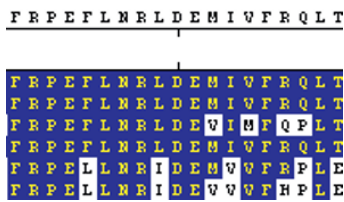

Spacer Signature IV

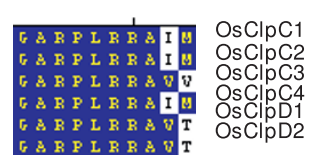

Spacer Signature $\mathrm{V}$

Figure 3 A. Relative positions of domains in rice ClpC and ClpD proteins. B. Consensus sequence of the different domains present in rice ClpC and ClpD proteins. Alignments were done using ClustalV of MegAlign module of DNASTAR and alignment pictures were modified for representation.

motif was in general present towards the $\mathrm{C}$-terminus except in case of OsClpC4 which had the tripeptide at its $\mathrm{N}$-terminus.

\section{Expression of rice class I Clp ATPase genes}

Microarray data at Genevestigator database (https:// www.genevestigator.ethz.ch/; [60]) were used for analyzing the transcript expression profiles of rice class I Clp ATPases in different tissues/developmental stages (Figures 4 and 5). In different developmental stages, the highest variation was found in expression of OsClpB-cyt: this gene showed minimal expression during germination, seedling, heading and flowering stages but showed high expression at milk and dough stages (Figure 4B). On the other hand, there was a gradual increase in the expression of $\mathrm{OsClpB-c}$ transcript from germination to milk stage and the expression declined during dough stage (Figure 4B). For expression of rice class I Clp ATPase genes in response to stresses, microarray profiling was carried out for analyzing expression during cold $\left(5^{\circ} \mathrm{C} ; 2 \mathrm{~h}\right.$ and $\left.4 \mathrm{~h}\right)$, heat $\left(42^{\circ} \mathrm{C} ; 10^{\prime}\right.$ and $\left.30^{\prime}\right)$ and oxidative stress $\left(10 \mathrm{mM} \mathrm{H}_{2} \mathrm{O}_{2} ; 1 \mathrm{~h}\right.$ and $\left.4 \mathrm{~h}\right)$ conditions. $\mathrm{ClpB}$ genes showed a notably enhanced expression during heat stress (Figure 4C). OsClpB-cyt showed enhanced expression during oxidative stress also although the magnitude of expression under oxidative stress was less as compared to heat stress. OsClpB-c and OsClpB-m showed almost identical response to the stresses (Figure 4C). Transcript expression for $C l p B$ genes with Q-PCR 
matched with microarray data. While all three $C l p B$ genes showed up-regulation under heat stress, the magnitude of the expression levels varied for the three genes (Figure 4D). Low levels of OsClpB-m and OsClpB-c transcripts were noted under unstressed conditions too. OsClpB-cyt transcript was strictly induced in response to heat stress (and to a lesser extent in response to oxidative stress; Figure 4D). The transcript abundance during heat shock was highest for $O s C l p B-m$ and lowest for OsClpB-c among the three ClpB ATPase genes. Semiquantitative RT-PCR analysis showed distinct heat shock inducibility in all three $\mathrm{ClpB}$ genes (Figure 4E). OsClpB-cyt was mainly heat shock inducible. This transcript also showed a somewhat low expression in response to cold stress. All three $\mathrm{ClpB}$ transcripts were noted to be induced in response to exogenous ABA application to a comparable extent in shoot and root tissues of rice seedlings (Figure 4F). Expression of OsClpBcyt was found to be much higher than other $C l p B$ isoforms in dry seeds of rice, based on real-time PCR analysis (Figure 4G).

OsClpC4 appeared to be transcriptionally silent in microarray at Genevestigator. OsClpC1 showed maximum expression among the various $\mathrm{ClpC}$ genes. Levels of $\mathrm{OsClpC1}$ transcript did not show much variation in expression; these transcripts were minimally expressed in endosperm. In general, there was almost similar expression profiles of $O s C l p D 1$ and $O s C l p D 2$ genes although there was variation in the magnitude of expression. OsClpD2 was seen to be expressed in anther and ovary but not in seed tissues (Figure 5A, B). Heat and oxidative stress inducibility was also relatively higher for $O s C l p C 2$ and $O s C l p D 1$ genes (Figure 5C). In the other Clp ATPases, only significant change marked was for low temperature inducibility of $O s C l p D 1$ (Figure 5D). Although microarray data showed that OsClpC2 was heat stress regulated, we did not find the same in semiquantitative RT-PCR.

\section{Localization of OsClpB-c and OsClpB-m proteins}

In silico analyses shown in Table 1 predicted OsClpB-c and OsClpB-m proteins to be present in chloroplasts and mitochondria, respectively. To confirm their localizations, we designed two constructs namely AtClpB-mCFP-1881-OsClpB-m-GFP and AtClpB-c-CFP-1881OsClpB-c in this study. In AtClpB-m-CFP-1881OsClpB-m-GFP construct, 90 amino acid long signal sequence (corresponding to 270 base pairs at the 5 ' end of ORF) from AtClpB-m were fused with CFP and used as a positive control and signal sequence from OsClpB$\mathrm{m}$ in fusion with GFP expression as a test system; expression was driven by using a bidirectional promoter from a pair of rice protease inhibitor genes, for both the reporter proteins. Similar strategy was employed in construction of AtClpB-c-CFP-1881-OsClpB-c plasmid. In this case, 84 amino acids long signal peptide (corresponding to 252 base pairs at the 5' end of ORF) were fused to CFP and used as a positive control. Both plasmids were shot separately for transient transformation of onion epidermal cells. The fluorescence emitting from GFP and CFP proteins in both the constructs colocalized (Figure 6). This suggests that OsClpB-m is localized to the same sub-cellular compartment as does the AtClpB-m. Likewise, OsClpB-c is localized to the same sub-cellular compartment as does the AtClpB-c.

Complementation of $\mathrm{S}$. cerevisiae $\Delta \mathrm{hsp} 104$ mutant by rice class I Clp ATPase proteins

Deletion of $h s p 104$ gene in yeast (Sc $\Delta h s p 104$ ) leads to thermosensitivity as the mutant cells are not able to survive heat shock (Figure 7A; [39]). Possible effect of different rice class I Clp ATPases in complementation of $\Delta$ hsp104 mutant yeast cells was next analyzed. Different class I Clp ATPases were cloned in pGV8 vector under the control of GPD constitutive promoter to yield constructs pGV8-OsClpB-cyt, pGV8-OsClpB-c, pGV8OsClpB-m, pGV8-OsClpC1, pGV8-OsClpC2 and pGV8OsClpD1 (Figure 7B). Plasmid DNA containing different class I Clp ATPases were linearized and transformed into Sc $\Delta$ hsp 104 cells and selected on a medium lacking uracil to yield Sc $\Delta h s p 104-\mathrm{pGV} 8-O s C l p B-c y t$, Sc $\Delta h s p 104$ pGV8-OsClpB-c, $\quad$ Sc $\Delta$ hsp104-pGV8-OsClpB-m, Sc $\Delta$ hsp104-pGV8-OsClpC1, Sc $\Delta$ hsp104-pGV8-OsClpC2 and Sc $\Delta$ hsp104-pGV8-OsClpD1 cell types. Sc $\Delta h s p 104$ cells transformed with AtHSP101 (Sc $\Delta h s p 104-$ AtHSP101) and ScHSP104 (ScAhsp104-ScHSP104) were used as positive control while Sc $\Delta h s p 104$ cells transformed with vector (Sc $\Delta h s p 104$-vector) were used as negative control. Thermotolerance assay was carried out by giving a pre-treatment of $60 \mathrm{~min}$ at $37^{\circ} \mathrm{C}$ and then exposing cells to heat shock for $30 \mathrm{~min}$ at $50^{\circ} \mathrm{C}$. Control and heat stressed cells were dotted on YPAD plates to a dilution of $10^{-4}$ and kept at $28^{\circ} \mathrm{C}$ for $48 \mathrm{~h}$ and photographed (Figure 7B). We noted that positive control Sc $\Delta$ hsp104-ScHSP104 grew better than Sc $\Delta h s p 104$ and Sc $\Delta$ hsp104-vector yeast cells. Positive effect was also seen in Sc $\Delta h s p 104-p G V 8-O s C l p B-c y t$, Sc $\Delta h s p 104-p G V 8-$ OsClpB-m, Sc $\Delta$ hsp104-pGV8-OsClpC1 and Sc $\Delta$ hsp104pGV8-OsClpD1 cell types. Remarkably, Sc $\Delta$ hsp104pGV8-OsClpD1 cells grew even better than ScAhsp104ScHSP104 cells.

\section{Discussion and conclusions}

We show in this study that rice genome has 9 entries (i. e. Os02g08490, Os02g32520, Os03g31300, Os04g32560, Os04g33210, Os11g16590, Os11g16770, Os12g12850 and Os05g44340) for the class I Clp ATPase protein family. In Arabidopsis, there are 6 class I Clp ATPase genes which specify $3 \mathrm{ClpB}$ proteins (At1g74310AtClpB-cyt; At5g15450-AtClpB-m; At2g25140-AtClpB- 


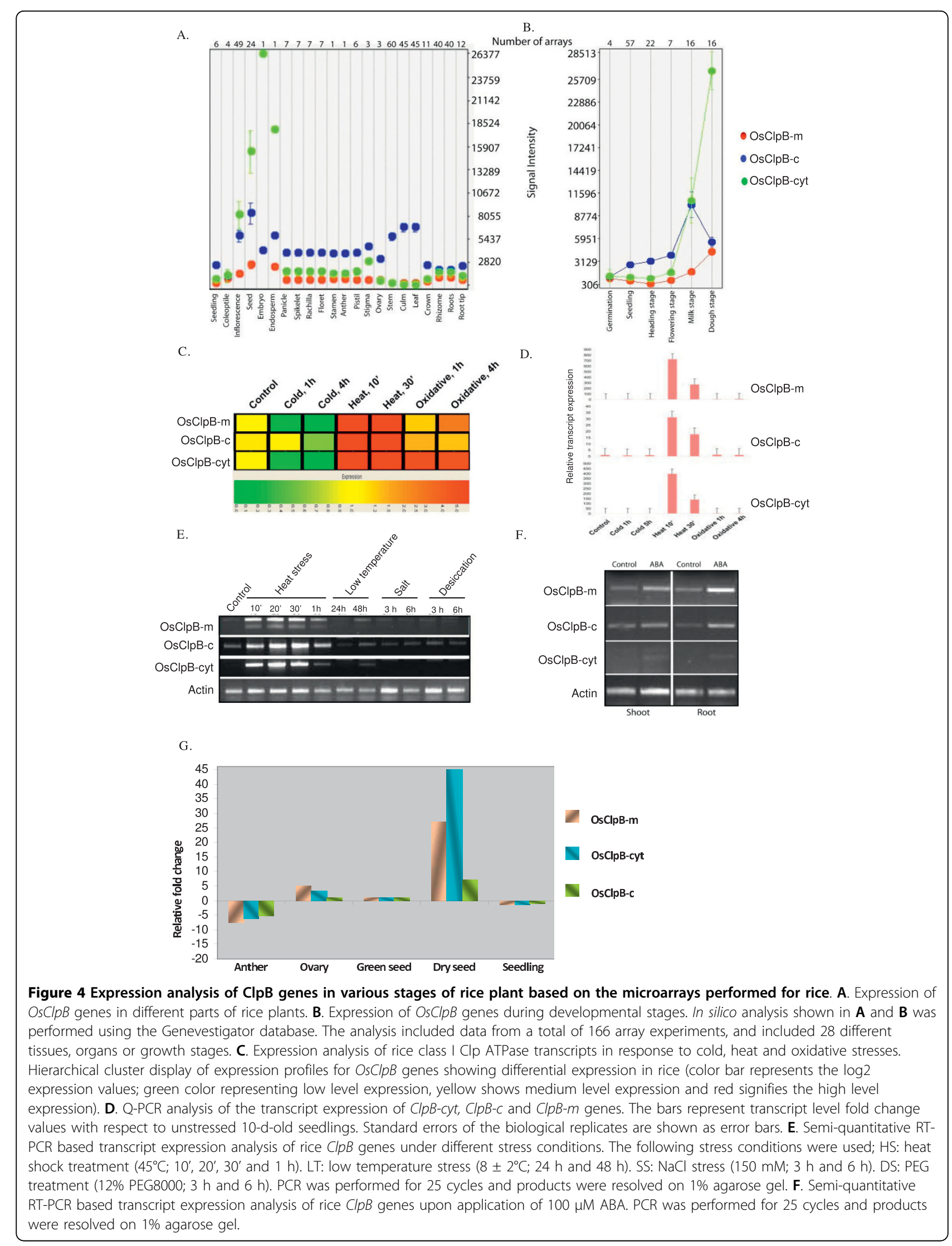




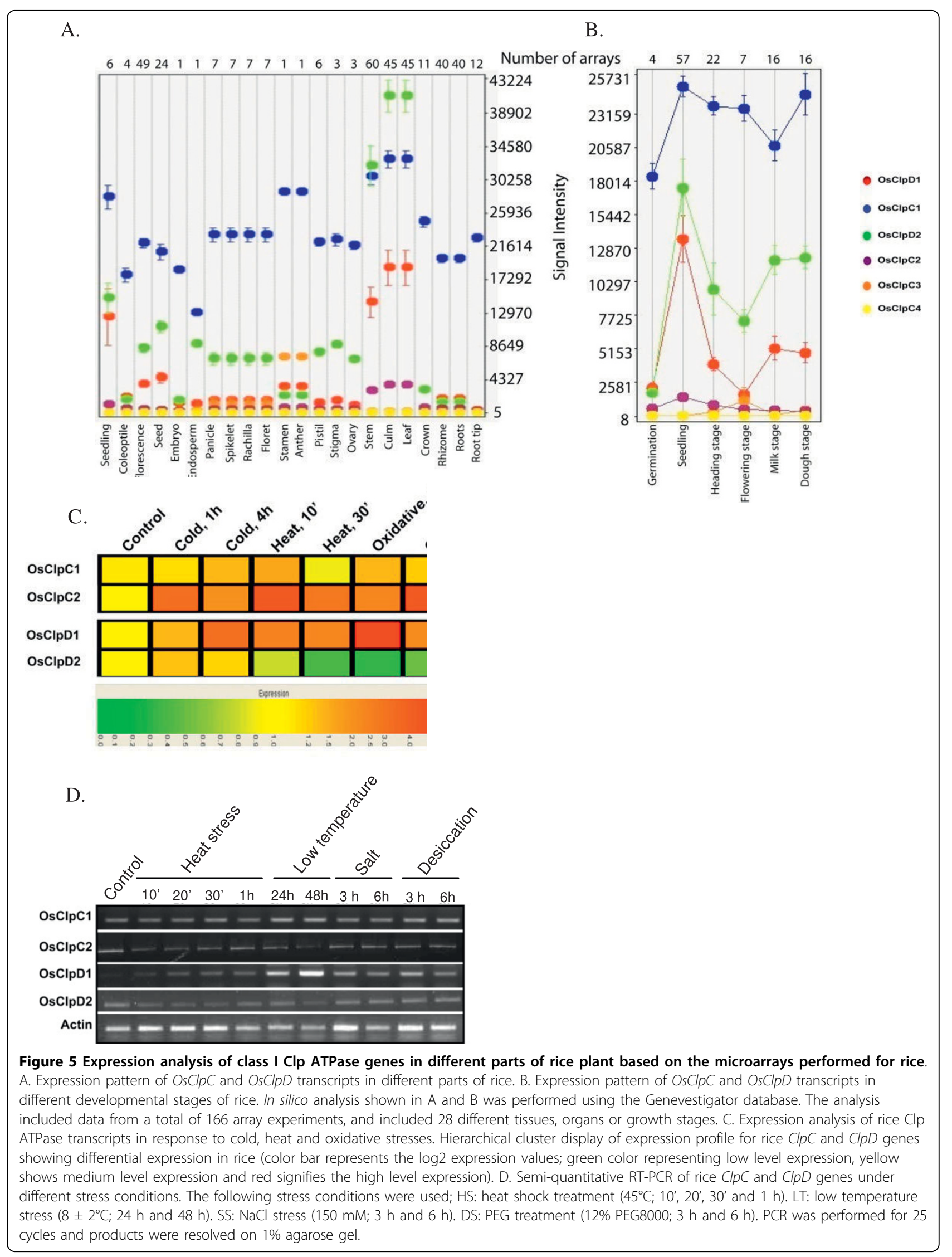




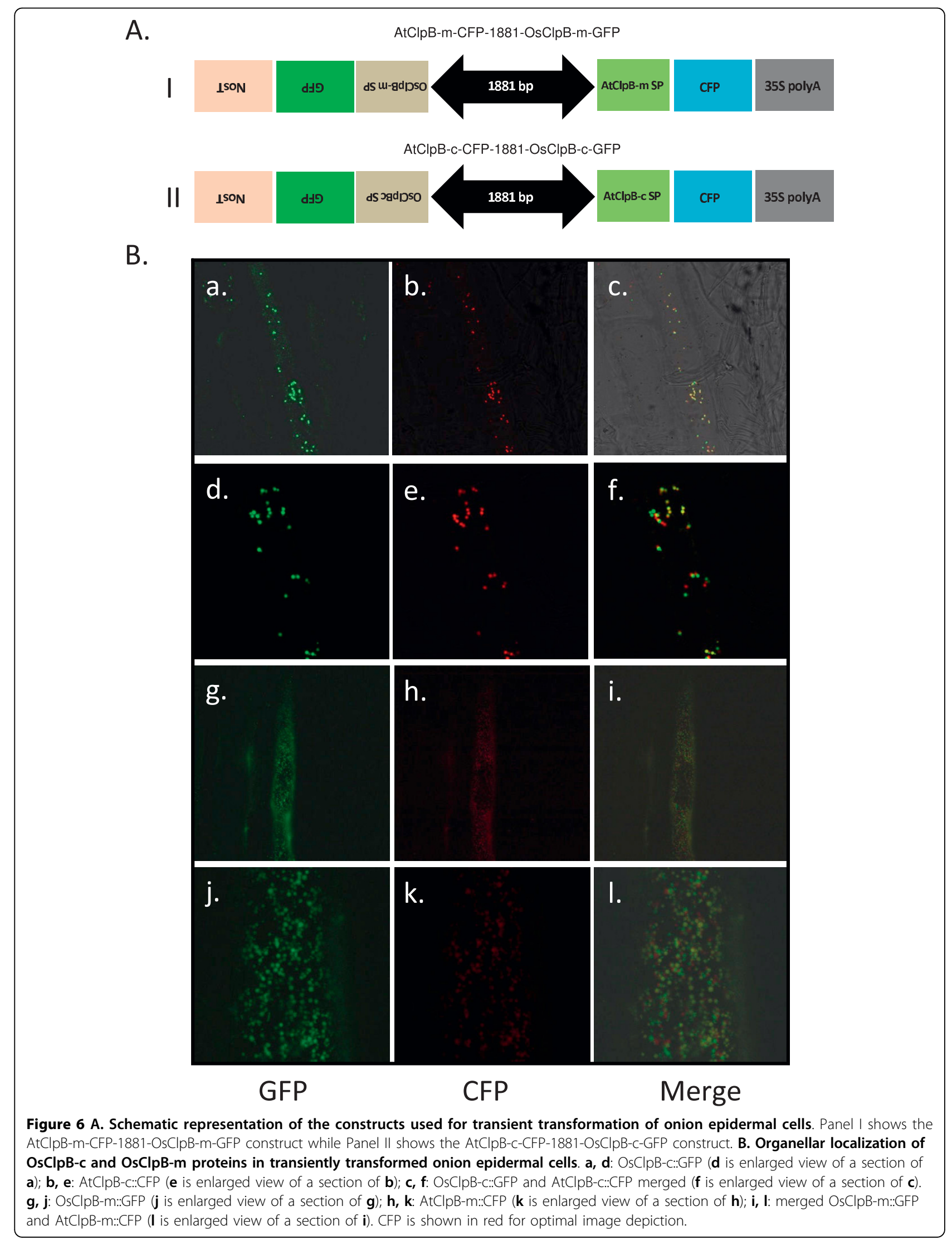


A.

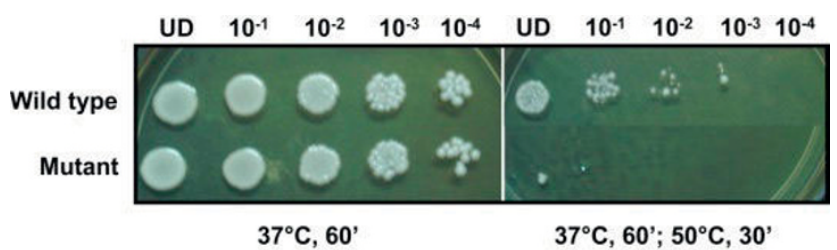

B.

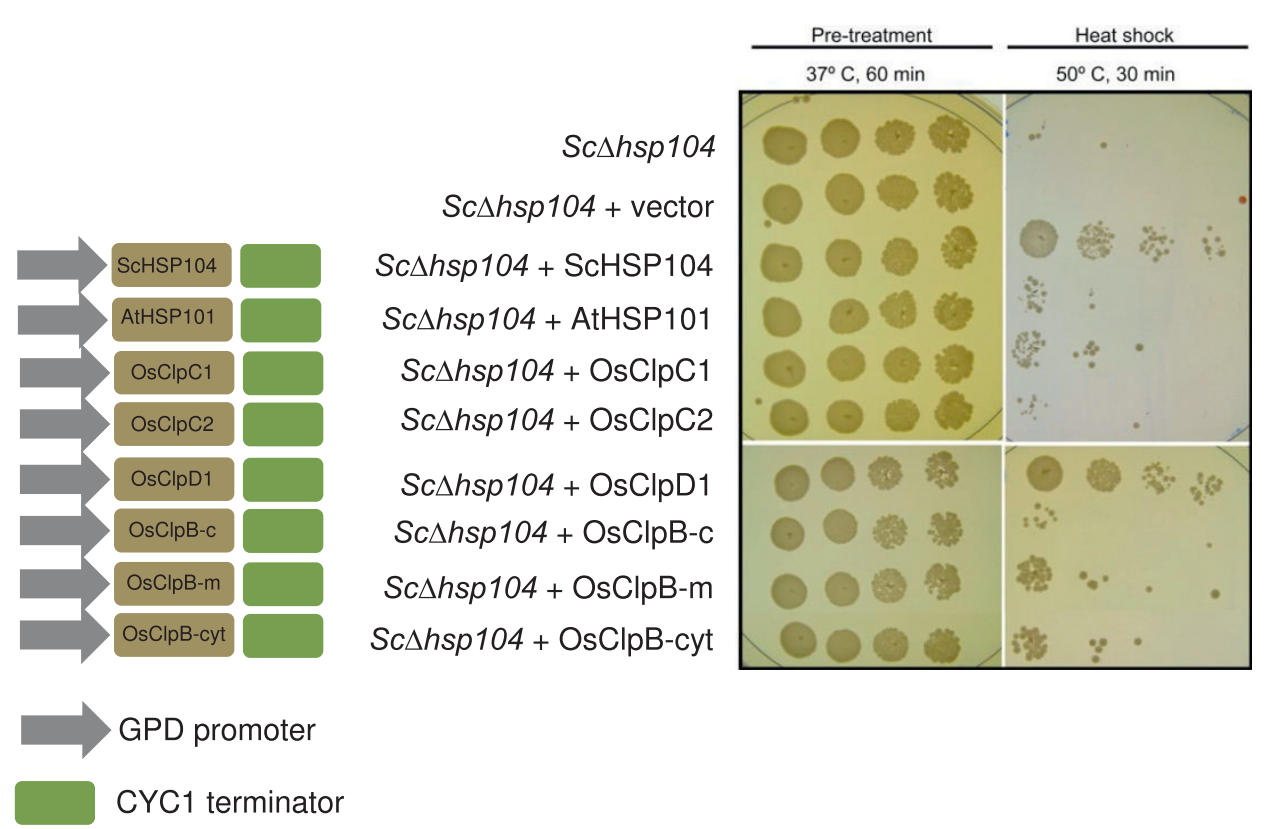

Figure 7 A. Thermotolerance assay of S. cerevisiae (wild type) and ScAhsp104 mutant cells. B. Complementation analysis of yeast $\Delta$ hsp 104 mutant with various Clp ATPase genes. Left panel shows schematic representation of the different constructs used to transform Sc $\Delta h s p 104$ mutant cells and right panel shows thermotolerance assays with the transformed yeast cells.

c), 2 ClpC proteins (C1, At5g50920; C2, At3g48870) and $1 \mathrm{ClpD}$ protein (At5g51070) [17]. From the comparative details, it appears that 9 rice loci specify $3 \mathrm{ClpB}$ (ClpBcyt, Os05g44340; ClpB-m, Os02g08490; ClpB-c, Os03g31300), 4 ClpC (ClpC1, Os04g32560; ClpC2, Os12g12580; ClpC3, Os11g16590; ClpC4, Os11g16770) and $2 \mathrm{ClpD}$ (ClpD1, Os02g32520; ClpD2, Os04g33210). Phylogenetic analysis using rice, Populus and Arabidopsis sequences showed that class I Clp ATPase sequences are significantly conserved. The tree showed three major clades, one each corresponding to $\mathrm{ClpB}, \mathrm{ClpC}$ and $\mathrm{ClpD}$ proteins (Figure 1). ClpB proteins were further categorized into cytoplasmic, chloroplastic and mitochondrial isoforms based on TargetP, Predotar, LOCTREE and PSORT database. Cytoplasmic ClpB members included OsClpB-cyt, At1g74310 and Pt101.72; chloroplastic ClpB included OsClpB-c, At5g15450, Pt106.69 and Pt108.53 and mitochondrial ClpB included OsClpB-m, At2g25140 and Pt98.74. Although OsClpC3 and OsClpC4 are considered members of $\mathrm{ClpC}$ class, these proteins appear somewhat different from $\mathrm{OsClpC} 1$ and $\mathrm{OsClpC} 2$ proteins. All ClpC proteins identified to date are localized to the chloroplast where they interact with the chloroplastic protease ClpP. From the in silico analysis, it appears that $\mathrm{ClpC} 3$ on the other hand may be chloroplast/mitochondria localized while $\mathrm{ClpC} 4$ is membrane bound protein. Recently, $\mathrm{AAA}^{+}$ATPase chaperone CoxD protein in Oligotropha carboxidovorans is found to be present exclusively in cytoplasmic membrane [61]. A Clp ATPase in Glycine max has also been found to be membrane associated [62]. High temperature causes modifications in membrane functions, associated with alteration of membrane fluidity. In plant cells, membrane-based processes such as photosynthesis and respiration are especially important. Vigh et al [63] proposed that any alterations in the plasma membrane microdomains are well suited for sensing stress and retailoring the expression of various classes of HSPs. The chances of interaction of membrane-associated HSPs with the proteins involved in signaling increases as these molecules are also concentrated in the membrane rafts. $\mathrm{ClpC} 4$ protein of rice may have such an implication. 
Importantly, OsClpC2 contained 691 nucleotides long intron in the 5 'UTR and further harbored five upstream ORFs (uORFs) in the 5'UTR. The role of these uORFs in regulation, if any, needs to be worked out. Both $O s C l p D 1$ and $O s C l p D 2$ genes towards their 5' ends showed a sterile alpha motif (SAM) domain containing protein (Os02g32530 and Os04g33220): MSU rice gene model predicts that OsClpD1 and Os02g32530 gene pair and OsClpD2 and Os04g33220 gene pair may give rise to natural sense/antisense transcripts (NATs). Further analysis of in vivo regulation of ClpD proteins may reflect the significance of this observation. Domain analysis showed that OsClpB-cyt protein contains various motifs which are typical of HSP100 proteins. Spacer signature II motif seen in $\mathrm{OsClpB}$ proteins was notably absent from OsClpCs and OsClpDs (Figures 2, 3). Complex formation between ClpA and ClpX with ClpP is reportedly mediated by a helix-loop-helix motif in which the tip of the loop contains an essential IGF/L tripeptide (P-element; [59]). Weibezahn et al [64] engineered a $\mathrm{ClpB}$ variant termed BAP (ClpB-ClpP-loop; a variant protein in which $\mathrm{ClpP}$ interacting site of ClpA has been engineered into $E$. coli $\mathrm{ClpB}$ ), which carried the P-element. Association of ClpP converted BAP from a refolding into a degrading disaggregase, demonstrating that this engineering brings in threading of aggregated proteins into the proteolytic chamber of ClpP. When rice class I Clp ATPase proteins were searched for the presence of IGF motif, it was seen that apart from OsClpB$\mathrm{m}$, OsClpB-c and OsClpB-cyt, all other proteins contained IGF/L tripeptide motif (Figures 2, 3). This observation may have an implication for differential function of $\mathrm{ClpB}$ as compared to other class I Clps. According to Kim et al [59], IGF/L tripeptide consensus is generally located between the sensor I and box VII motifs. However, OsClpC4 contained this motif towards the N-terminus. This may have some relation to the fact that unlike all other Clps, OsClpC4 is the only rice Clp that appears to be associated with the plasma membrane.

Cross-induction of HSP genes by diverse stresses is known [11,13]. Zou et al [65] have recently shown that the expression of nine different OsHSP genes was affected differentially by heat, cold, salt, desiccation as well as ABA. $\mathrm{Hu}$ et al [8] noted an extensive overlap of transcript levels in rice HSFs and HSPs in response to different stresses. Likewise, Mittal et al [9] noted crossinduction of HSF transcripts by diverse stresses in rice seedlings. On the same line, ClpATPase genes showed stress-related transcript expression. Agarwal et al [39] reported that $O s C l p B-c y t / H S P 100$ transcript in rice seedlings is induced strongly by heat and this transcript remains unaffected in response to salt stress, water stress, low temperature stress and ABA application. $\mathrm{Hu}$ et al [8] noted that $O s C l p B-c y t$ was regulated by heat shock as well as drought. In this study, microarray analysis showed that $O s C l p B$-cyt transcript was up-regulated more than 5-folds both during heat stress as well as oxidative stress. OsClpB-cyt transcript was induced after low temperature stress (Figure $4 \mathrm{E}$ ). This study is the first report for the cold induction of OsClpB-cyt, though at low levels. Wu et al [66] reported that rice HSP100 promoter responds to desiccation stress. In the experimental conditions used in the current study (PEG treatment), we failed to note induction of OsClpB-cyt transcript in response to desiccation stress. OsClpB-c was up-regulated during heat stress by up to 5 -folds and during oxidative stress by up to 1.5 folds based on microarray analysis (Figure $4 C$ ). Q-PCR data showed that as with $O s C l p B$-cyt, the relative abundance of $O s C l p B-c$ transcripts was far more responsive during heat stress as compared to oxidative stress. OsClpB-m gene, like its counterpart gene in Arabidopsis, was found to be heat and oxidative stress up-regulated (Figure 4). Q-PCR data showed that transcript abundance of OsClpB-m was highest during heat stress among the three $O s C l p B$ genes. On the other hand, AtClpB-m showed lowest transcript abundance among its different ClpB isoforms [17]. In a study on transcriptional profiling of genes responsive to hormonal treatments in rice, HSP100 transcript was found to be specifically induced in response to ABA [67]. We observe that transcriptionally, $O s C l p B-m$ and $O s C l p B-c$ respond more to ABA than OsClpB-cyt (Figure 4F).

$O s C l p C 1$ transcripts did not undergo any change under stress conditions while $\mathrm{OsClpC2}$ was seen to be up-regulated ( 3-4 folds) under heat, cold and oxidative stress conditions as seen in microarray experiment although we did not find the same upregulation in semi-quantitative RT-PCR analysis (Figure 5C). No amplicons were detected for $\mathrm{OsClpC3}$ and $\mathrm{OsClpC4}$ in the semi-quantitative RT-PCR analysis. This may indicate that these loci may in fact be transcriptionally silent under the conditions tested. However, in silico analysis of publicly-available microarray database shows $\mathrm{OsClpC3}$ expression in stem, culm and leaf tissues (Figure 5A). Evidence for expression of $\mathrm{OsClpC4}$ is yet awaited. Shen et al [68] reported that $O s C l p D 1$ is induced by water deficit and temperature stress in vegetative tissues. We observed that this gene was up-regulated by different stresses. In microarray data, OsClpD2 showed down-regulation during heat and oxidative stresses and a marginal up-regulation in cold stress (Figure 5C).

AtClpB-m and AtClpB-c have been shown to be localized to mitochondria and chloroplast, respectively [17]. We found that OsClpB-m is localized to the same location in the cell as AtClpB-m. Likewise, we noted that OsClpB-c is localized to the same location as AtClpB-c. We thus show that OsClpB-m and OsClpB-c are 
localized to mitochondria and chloroplast, respectively (Figure 6). It therefore, appears that these proteins may have specific functions in cellular organelles.

Yeast expressing HSP104 are typically 100- to 1000fold more thermotolerant than yeast lacking HSP104, thus demonstrating the critical requirement for this protein in cell survival during extreme heat stress [69]. Arabidopsis ClpB-Cyt/HSP101 has been shown to overcome the temperature sensitivity of yeast $\Delta$ hsp 104 mutant [38]. Similar observations were noted for the ClpB-Cyt/ HSP100 proteins from soybean [70] and rice [39]. This fact prompted us to analyze ability of diverse class I Clp genes in yeast mutant complementation assay. OsClpBcyt showed reasonably good complementation ability. The capability of OsClpB-m appeared comparable to OsClpB-cyt in conferring tolerance. Our observation actually matches to an earlier experiment done with yeast [71]. This group expressed yeast Hsp78 protein which is mitochondrial isoform of the yeast cytoplasmic Hsp104 protein, in the cytoplasm of the Hsp104 mutant yeast cells. They noted that yeast Hsp78 protein complements the cytoplasmic Hsp104 yeast mutation. This experiment indicates that the organellar and the cytoplasmic ClpBs may have some degree of redundancy in their substrate recognition. Further, the target substrate proteins of different Clps are not yet defined. In due course when target proteins are established, it should be possible to address the question of mitochondrial $\mathrm{ClpB}$ complementing the cytoplasmic yeast hsp104 mutation more deeply. A significant observation in this assay test was the fact that OsClpD1 restores the mutation defect of the $S c \Delta h s p 104$ yeast cells to a significant extent; Sc $\Delta$ hsp104-pGV8-OsClpD1 showed growth comparable to that of the ScAhsp104-ScHSP104 yeast cells. ClpD expression in Arabidopsis has previously been seen to be associated during senescence [56] but there is no study that links expression of this gene to heat stress. The detailed mechanism behind this role of OsClpD1 remains to be worked out. It should be relevant to analyze how OsClpD1 expression alters transcript profiling in $\Delta h s p 104$ mutant yeast cells. It should also be relevant to generate transgenic plants with ectopically higher ClpD1 protein and analyze their stress phenotype. Weibezahn et al [64] found that the development of thermotolerance in E. coli relies on the ClpB/KJE-mediated reactivation of aggregated proteins, whereas the removal of protein aggregates by degradation does not confer thermotolerance. Similarly in yeast, Tessarz et al [72] noted that the degradation of aggregated proteins results in loss of thermotolerance. They reported that the removal of aggregated proteins by HAP and ClpP is not sufficient for yeast cells to survive a severe heat shock, but survival demands on the reactivation of aggregated proteins. It can thus be inferred that disaggregation and reactivation of proteins is essential for cell survival after extreme heat stress, whereas the degradation of aggregated proteins is insufficient. It is possible that expression of OsClpD1 does this activity more efficiently than other class I Clps and hence its expression results in more thermotolerance than noted for other rice class I Clp proteins. Finally, it needs to be mentioned that although different Clp ATPases are noted to complement yeast hsp104 mutation in this study, it is possible that variations in expression levels of rice Clps in yeast which have not been determined, may also affect complementation efficiencies.

Finally, we wish to herein draw a comparable picture of Arabidopsis and rice class I Clp ATPases. There are some major differences in these two species for the number of $\mathrm{ClpB}, \mathrm{ClpCs}$ and $\mathrm{ClpDs}$ nuclear genes. While Arabidopsis has 2 and $1 \mathrm{ClpC}$ and $\mathrm{ClpD}$ members, respectively, rice appears to contain 4 and $2 \mathrm{ClpC}$ and ClpD members, respectively. On the other hand, number of ClpB proteins appears same (3) in both rice and Arabidopsis. Both in rice and Arabidopsis, one each of ClpB type is present in cytoplasm, chloroplasts and mitochondria. It should be relevant to extend the above observations further to analyze what implications these might have in regulating heat response in these two contrasting plant species.

\section{Methods}

\section{Growth conditions of rice and stress treatments}

Rice [Oryza sativa L; cultivar Pusa Basmati (PB1), an indica type] seeds were washed with mild detergent and the detergent was removed by washing the seeds thoroughly with running tap water. Seeds were subsequently rinsed with $70 \%$ ethanol at room temperature for $45 \mathrm{~s}$ and washed with sterile distilled water 5-6 times to remove traces of ethanol. The seeds were soaked overnight at RT in dark before placing on cotton bed in a tray for germination. Seedlings were grown at $28 \pm 2^{\circ} \mathrm{C}$ and $14 \mathrm{~h}$ light $10 \mathrm{~h}$ dark cycle maintained in growth room (light intensity $\sim 250$ $\mu \mathrm{mol} \mathrm{m} \mathrm{m}^{-2}$, humidity $\sim 40 \%$ ). For temperature stress, uniform-sized seedlings were transferred to beakers, which contained distilled water at $42 \pm 1^{\circ} \mathrm{C}$ for heat stress (HS), at $5 \pm 1^{\circ} \mathrm{C}$ for cold stress (CS), and 10 $\mathrm{mM} \mathrm{H}_{2} \mathrm{O}_{2}$ at $28 \pm 2^{\circ} \mathrm{C}$ for oxidative stress, and maintained at the requisite temperatures in BOD (for different time intervals as shown). For RT-PCR analysis, rice seedlings were subjected to heat, cold, salt and desiccation stresses. Salt stress was imposed by placing seedlings in beakers containing cotton pads soaked with $\mathrm{NaCl}$ solution, instead of distilled water. Roots and shoots were harvested and frozen in liquid $\mathrm{N}_{2}$ after desired durations of stress treatment. Desiccation stress was implied to rice seedlings by keeping in $12 \%$ 
PEG4000 as indicated. Subsequent to completion of the stress intervals, tissues were harvested, frozen in liquid nitrogen and kept at $-80^{\circ} \mathrm{C}$.

\section{Semi-quantitative reverse transcriptase PCR, Q-PCR and} Microarray analysis

Total RNA was isolated from the control and stressed tissues from PB1 as per the standard protocol [73]. For semi-quantitative reverse transcriptase PCR, complementary DNAs were synthesized from $5 \mu \mathrm{g}$ of total RNA primed with oligo ( $\mathrm{dT}$ ) primers using M-MLV reverse transcriptase (MBI Fermentas, Lithuania). RTPCR amplification parameters were optimized to analyze individual target genes and gene specific primers were used. $\beta$-actin was amplified as an internal control. QPCR and microarray analysis were carried out as described earlier [9]. All primer details are provided in Additional file 6. Raw microarray data have been deposited in the Gene Expression Omnibus (GEO) database at the National Center for Biotechnology Information (NCBI) under the accession number GSE19983.

\section{Sequence analysis}

$\mathrm{ClpB}$ homologs in rice were identified by performing BLAST search at the National Centre for Biotechnology Information http://www.ncbi.nlm.nih.gov/BLAST/ and MSU Rice Genome Annotation Project Database and Resource http://rice.plantbiology.msu.edu/ using the sequence of the ClpB-cyt/HSP100 (Os05g44340; Accession number AJ316025) as the query. The number and position of exons and introns in different genes were determined by comparison of the cDNAs with their corresponding genomic DNA sequences as well as by Spidey program http://www.ncbi.nlm.nih.gov/spidey/. In specific cases because of the lack of complete cDNA information, the ORFs were used for this analysis. The position of each gene on rice chromosomes was found by BLASTN search in genomic sequence of rice chromosome pseudomolecules available at MSU Rice Genome Annotation Project Database and Resource (Release 5). Multiple sequence alignments were done using the Clustal X (version 1.83) program [74] and the phylogenetic analysis was carried out by neighbor joining method [75]. The unrooted phylogenetic tree was displayed using the Treeview program [76]. The DNA and protein sequence analyses were performed using DNASTAR software.

Cloning of signal peptides to confirm localization of OsClpB-m and OsClpB-c and transient transformation of onion epidermal cells

The sequences corresponding to signal peptides of OsClpB-c and OsClpB-m were amplified using AK069123 and AK287906 clones, respectively, as templates for PCR which were cloned upstream of GFP in pCAMBIA1302. Subsequently, signal peptide-GFP fusions along with NosT were amplified and cloned in
pBCSK in BamHI and EcoRI sites and the plasmids were named as pBCSK-OsClpB-c-GFP and pBCSKOsClpB-m-GFP. The signal peptides corresponding to Arabidopsis ClpB-c and ClpB-m were PCR amplified using Arabidopsis cDNA. The amplicons were cloned in the vector pAVA574 [77] to generate a fusion with CFP. Subsequently the signal peptide-CFP fusions were amplified along with the $35 \mathrm{~S}$ terminator and cloned in pBCSK-OsClpB-c-GFP or pBCSK-OsClpB-m-GFP vectors. The $1881 \mathrm{bp}$ bidirectional promoter from a pair of rice protease inhibitor genes [78], was introduced in BamHI site. The plasmids so generated were named as AtClpB-m-CFP-1881-OsClpB-m-GFP and AtClpB-cCFP-1881-OsClpB-c and were subsequently used for transient assays in onion epidermal cells as described previously [79] and analyzed for GFP and CFP expression using a Leica TCS SP5 inverted confocal microscope.

Yeast transformation and thermotolerance assays of recombinant yeast cells

Yeast transformation was carried out as described previously $[39,79]$. For thermotolerance of yeast cells, a secondary culture of yeast cells (initial $\mathrm{OD}_{600} 0.05$ ) was started and incubated $\left(25^{\circ} \mathrm{C}, 200 \mathrm{rpm}\right)$ till $\mathrm{OD}_{600}$ reaches $0.15(\sim 3 \mathrm{~h})$. $\mathrm{OD}_{600}$ of the secondary culture was also measured and if there was slight variation, it was normalized. Aliquots of $200 \mu \mathrm{l}$ of the yeast cells from all the strains was made in MCTs which were placed immediately in a water bath set at $50^{\circ} \mathrm{C}$ for 30 min. For the constructs in $S c \Delta h s p 104$ cells, cells were given a heat pre-treatment at $37^{\circ} \mathrm{C}$ for $1 \mathrm{~h}$. After stress, MCTs were immediately plunged into ice. For spotting, 10 fold serial dilutions (till $10^{-4}$ ) of the cells were prepared in sterile water and $5 \mu \mathrm{l}$ of each was dotted on YPD-agar plates (YPD containing $1.8 \% \mathrm{w} / \mathrm{v}$ agar). The plates were dried in the laminar flow and incubated at $30^{\circ} \mathrm{C}$ for $2 \mathrm{~d}$.

\footnotetext{
Additional file 1: Properties of class I Clp ATPase proteins from Populus trichocarpa and Arabidopsis. The tables describe the properties of class I Clp ATPase proteins.

Click here for file

[http://www.biomedcentral.com/content/supplementary/1471-2164-1195-S1.DOC ]

Additional file 2: Genomic organization of rice Clp ATPase genes. Genomic organization of rice Clp ATPase genes based on the comparison of ORFs and genomic DNA. The exon-intron distribution is marked for the coding region of the genes and does not involve the UTRs. The scale above represents the nucleotides in kb. Black lines represent the introns while grey boxes represent the exons. The representation is to the scale.

Click here for file

[http://www.biomedcentral.com/content/supplementary/1471-2164-1195-S2.PPT ]
} 
Additional file 3: Domain architecture of rice ClpB proteins

Schematic representation of various domains present in rice ClpB proteins. The proteins were aligned with respect to first NBD. SMART

database was used to visualize the domains.

Click here for file

[http://www.biomedcentral.com/content/supplementary/1471-2164-1195-S3.PPT ]

Additional file 4: Structural aspects of rice ClpB proteins. A. Structure of $A$. thaliana ClpB monomer. B. Monomeric structures of OsClpB proteins as predicted at I-TASSER server. Structures with the highest Cscore were chosen for all the proteins. C. Predicted binding sites present in the rice $\mathrm{ClpB}$ proteins. The predicted binding sites are shown in green spheres while $\mathrm{N}$ - and $\mathrm{C}$-terminus in the model are marked by blue and red spheres, respectively.

Click here for file

[http://www.biomedcentral.com/content/supplementary/1471-2164-1195-S4.PPT ]

Additional file 5: Details of the binding site predicted in OsClpB proteins using I-TASSER. The binding sites were predicted in OsClpB proteins using I-TASSER.

Click here for file

[http://www.biomedcentral.com/content/supplementary/1471-2164-1195-S5.DOC ]

Additional file 6: Primers used in the current study. List of all the primers used in the analysis.

Click here for file

[http://www.biomedcentral.com/content/supplementary/1471-2164-1195-S6.DOC ]

\section{Abbreviations}

Clp: Casenolytic protease; HSP: heat shock protein; HS: heat stress; PCR: polymerase chain reaction.

\section{Acknowledgements}

AG thanks Centre for Plant Molecular Biology, Department of Biotechnology, Government of India for the project grants. AS and DM acknowledges CSIR for the fellowship grants. US thanks CPMB for the fellowship award. We also thank Rice Genome Resource Centre, Japan for providing us the full length cDNAs. We wish to thank Dr Surajit Sarkar, Department of Genetics, University of Delhi South Campus, for help in confocal microscopy.

\section{Authors' contributions}

AS participated in the designing of the experiments and carried out the experiments. The computing work was done by AS. AS and US performed the semi-quantitative RT-PCRs and yeast thermotolerance assays. AS and DM performed the microarray and Q-PCR experiments. AG designed the experiments undertaken in this study. AG made contributions in the analysis of the data and interpretation of the findings. AS and AG together drafted the manuscript. All the authors read and approved the final manuscript.

Received: 28 September 2009

Accepted: 8 February 2010 Published: 8 February 2010

\section{References}

1. Peng S, Huang J, Sheehy JE, Laza RC, Visperas RM, Zhong X, Centeno GS, Khush GS, Cassman KG: Rice yields decline with higher night temperature from global warming. Proc Natl Acad Sci 2004, 101(27):9971-9975.

2. Grover A, Chandramouli A, Agarwal S, Katiyar-Agarwal S, Agarwal M, Sahi C. Transgenic rice for tolerance against abiotic stresses. Rice Improvement in the Genomic Era Hawarth Press USADutta SK 2009, 237-267.

3. Singh $A$, Grover A: Genetic engineering for heat tolerance in plants. Physiol Mol Biol Plants 2008, 14:155-166.

4. Frank G, Pressman E, Ophir R, Althan L, Shaked R, Freedman M, Shen S, Firon N: Transcriptional profiling of maturing tomato (Solanum lycopersicum L.) microspores reveals the involvement of heat shock proteins, ROS scavengers, hormones, and sugars in the heat stress response. Journal of Experimental Botany 2009, 60(13):3891-3908.
5. IRGSP: The map-based sequence of the rice genome. Nature 2005 436(7052):793-800

6. Yu J, Hu S, Wang J, Wong GK, Li S, Liu B, Deng Y, Dai L, Zhou Y, Zhang X, et al: A draft sequence of the rice genome (Oryza sativa L. ssp. indica). Science 2002, 296(5565):79-92.

7. Meier S, Gehring C, MacPherson C, Kaur M, Maqungo M, Reuben S, Muyanga S, Shih M-D, Wei F, Wanchana S, et al: The promoter signatures in rice LEA genes can be used to build a co-expressing LEA gene network. Rice 2008, 1:177-187.

8. Hu W, Hu G, Han B: Genome-wide survey and expression profiling of heat shock proteins and heat shock factors revealed overlapped and stress specific response under abiotic stresses in rice. Plant Sci 2009, 176:583-590.

9. Mittal D, Chakrabarti S, Sarkar A, Singh A, Grover A: Heat shock factor gene family in rice: genomic organization and transcript expression profiling in response to high temperature, low temperature and oxidative stresses. Plant Physiol Biochem 2009, 47(9):785-795.

10. Ouyang Y, Chen J, Xie W, Wang L, Zhang Q: Comprehensive sequence and expression profile analysis of Hsp20 gene family in rice. Plant Molecular Biology 2009, 70(3):341-57.

11. Sarkar NK, Kim YK, Grover A: Rice sHsp genes: genomic organization and expression profiling under stress and development. BMC Genomics 2009, 10(1):393.

12. Singla SL, Grover A: Antibodies raised against yeast HSP 104 cross-react with a heat- and abscisic acid-regulated polypeptide in rice. Plant Molecular Biology 1993, 22(6):1177-1180.

13. Pareek A, Singla SL, Grover A: Immunological evidence for accumulation of two high-molecular-weight (104 and $90 \mathrm{kDa}$ ) HSPs in response to different stresses in rice and in response to high temperature stress in diverse plant genera. Plant Molecular Biology 1995, 29(2):293-301.

14. Singla SL, Pareek A, Kush AK, Grover A: Distribution patterns of 104 kDa stress-associated protein in rice. Plant Molecular Biology 1998, 37(6):911-919.

15. Batra G, Chauhan VS, Singh A, Sarkar NK, Grover A: Complexity of rice Hsp100 gene family: lessons from rice genome sequence data. Journal of Biosciences 2007, 32(3):611-619.

16. Katiyar-Agarwal $\mathrm{S}$, Agarwal M, Gallie DR, Grover A: Search for cellular functions of plant Hsp100/Clp family proteins. Crit Rev Plant Sci 2001, 20:277-295.

17. Lee U, Rioflorido I, Hong SW, Larkindale J, Waters ER, Vierling E: The Arabidopsis ClpB/Hsp100 family of proteins: chaperones for stress and chloroplast development. Plant J 2007, 49(1):115-127.

18. Hwang BJ, Park WJ, Chung CH, Goldberg AL: Escherichia coli contains a soluble ATP-dependent protease (Ti) distinct from protease La. Proc Natl Acad Sci 1987, 84(16):5550-5554.

19. Katayama-Fujimura Y, Gottesman S, Maurizi MR: A multiple-component, ATP-dependent protease from Escherichia coli. The Journal of Biological Chemistry 1987, 262(10):4477-4485.

20. Laskowska E, Kuczynska-Wisnik D, Skorko-Glonek J, Taylor A: Degradation by proteases Lon, Clp and HtrA, of Escherichia coli proteins aggregated in vivo by heat shock; HtrA protease action in vivo and in vitro. Molecular Microbiology 1996, 22(3):555-571.

21. Frickey T, Lupas AN: Phylogenetic analysis of AAA proteins. Journal of Structural Biology 2004, 146(1-2):2-10.

22. Neuwald AF, Aravind L, Spouge JL, Koonin EV: AAAt: A class of chaperone-like ATPases associated with the assembly, operation, and disassembly of protein complexes. Genome Research 1999, 9(1):27-43.

23. Schirmer EC, Glover JR, Singer MA, Lindquist S: HSP100/Clp proteins: a common mechanism explains diverse functions. Trends Biochem Sci 1996, 21(8):289-296

24. Adam Z, Adamska I, Nakabayashi K, Ostersetzer O, Haussuhl K, Manuell A, Zheng B, Vallon O, Rodermel SR, Shinozaki K, et al: Chloroplast and mitochondrial proteases in Arabidopsis. A proposed nomenclature. Plant Physiol 2001, 125(4):1912-1918.

25. Wickner S, Gottesman S, Skowyra D, Hoskins J, McKenney K, Maurizi MR: A molecular chaperone, ClpA, functions like DnaK and DnaJ. Proc Natl Acad Sci 1994, 91(25):12218-12222

26. Wawrzynow A, Wojtkowiak D, Marszalek J, Banecki B, Jonsen M, Graves B, Georgopoulos C, Zylicz M: The ClpX heat-shock protein of Escherichia coli, the ATP-dependent substrate specificity component of the ClpP- 
ClpX protease, is a novel molecular chaperone. The EMBO Journal 1995, 14(9):1867-1877.

27. Kessel M, Maurizi MR, Kim B, Kocsis E, Trus BL, Singh SK, Steven AC: Homology in structural organization between E. coli ClpAP protease and the eukaryotic 26 S proteasome. Journal of Molecular Biology 1995, 250(5):587-594.

28. Rohrwild M, Pfeifer G, Santarius U, Muller SA, Huang HC, Engel A Baumeister W, Goldberg AL: The ATP-dependent HsIVU protease from Escherichia coli is a four-ring structure resembling the proteasome. Nature Structural Biology 1997, 4(2):133-139.

29. Porankiewicz J, Wang J, Clarke AK: New insights into the ATP-dependent Clp protease: Escherichia coli and beyond. Molecular Microbiology 1999, 32(3):449-458

30. Woo KM, Kim Kl, Goldberg AL, Ha DB, Chung CH: The heat-shock protein ClpB in Escherichia coli is a protein-activated ATPase. The Journal of Biological Chemistry 1992, 267(28):20429-20434.

31. Mogk A, Tomoyasu T, Goloubinoff $P$, Rudiger S, Roder D, Langen $H_{\text {, }}$ Bukau B: Identification of thermolabile Escherichia coli proteins: prevention and reversion of aggregation by DnaK and ClpB. The EMBO Journal 1999, 18(24):6934-6949.

32. Motohashi K, Watanabe $Y$, Yohda M, Yoshida M: Heat-inactivated proteins are rescued by the DnaK.J-GrpE set and ClpB chaperones. Proc Natl Acad Sci 1999, 96(13):7184-7189.

33. Zolkiewski M: ClpB cooperates with DnaK, DnaJ, and GrpE in suppressing protein aggregation. A novel multi-chaperone system from Escherichia coli. The Journal of Biological Chemistry 1999, 274(40):28083-28086.

34. Doyle SM, Hoskins JR, Wickner S: Collaboration between the ClpB AAA+ remodeling protein and the DnaK chaperone system. Proc Natl Acad SC 2007, 104(27):11138-11144.

35. Hong SW, Vierling E: Mutants of Arabidopsis thaliana defective in the acquisition of tolerance to high temperature stress. Proc Natl Acad SC 2000, 97(8):4392-4397.

36. Hong SW, Vierling E: Hsp101 is necessary for heat tolerance but dispensable for development and germination in the absence of stress. Plant J 2001, 27(1):25-35

37. Nieto-Sotelo J, Martinez LM, Ponce G, Cassab Gl, Alagon A, Meeley RB, Ribaut JM, Yang R: Maize HSP101 plays important roles in both induced and basal thermotolerance and primary root growth. Plant Cell 2002, 14(7):1621-1633.

38. Queitsch C, Hong SW, Vierling E, Lindquist S: Heat shock protein 101 plays a crucial role in thermotolerance in Arabidopsis. Plant Cell 2000, 12(4):479-492

39. Agarwal M, Sahi C, Katiyar-Agarwal S, Agarwal S, Young T, Gallie DR, Sharma VM, Ganesan K, Grover A: Molecular characterization of rice hsp101: complementation of yeast hsp104 mutation by disaggregation of protein granules and differential expression in indica and japonica rice types. Plant Molecular Biology 2003, 51(4):543-553.

40. Katiyar-Agarwal S, Agarwal M, Grover A: Heat-tolerant basmati rice engineered by over-expression of hsp101. Plant Molecular Biology 2003, 51(5):677-686

41. Keeler SJ, Boettger CM, Haynes JG, Kuches KA, Johnson MM, Thureen DL, Keeler CL Jr, Kitto SL: Acquired thermotolerance and expression of the HSP100/ClpB genes of lima bean. Plant Physiol 2000, 123(3):1121-1132.

42. Yang JY, Sun $Y$, Sun AQ, Yi SY, Qin J, Li MH, Liu J: The involvement of chloroplast HSP100/ClpB in the acquired thermotolerance in tomato. Plant Molecular Biology 2006, 62(3):385-395.

43. Moore T, Keegstra K: The involvement of chloroplast HSP100/ClpB in the acquired thermotolerance in tomato. Plant Molecular Biology 1993, 21(3):525-537.

44. Nakabayashi K, Ito M, Kiyosue T, Shinozaki K, Watanabe A: Identification of clp genes expressed in senescing Arabidopsis leaves. Plant \& Cell Physiology 1999, 40(5):504-514.

45. Shanklin J, DeWitt ND, Flanagan JM: The stroma of higher plant plastids contain ClpP and ClpC, functional homologs of Escherichia coli ClpP and ClpA: an archetypal two-component ATP-dependent protease. Escherichia coli 1995, 7(10):1713-1722.

46. Zheng B, Halperin T, Hruskova-Heidingsfeldova O, Adam Z, Clarke AK: Characterization of Chloroplast Clp proteins in Arabidopsis: Localization tissue specificity and stress responses. Arabidopsis 2002, 114(1):92-101.
47. Kirstein J, Schlothauer T, Dougan DA, Lilie H, Tischendorf G, Mogk A, Bukau B, Turgay $\mathrm{K}$ : Adaptor protein controlled oligomerization activates the $\mathrm{AAA}^{+}$protein ClpC. The EMBO Journal 2006, 25(7):1481-1491.

48. Desimone $M$, Weib-Wichart $C$, Wagner $E$, Altenfeld $U$, Johanningnener $U$ : Immunological studies on the Clp-protease in chloroplasts: evidence for the formation of ClpC/P complex. Bot Acta 1997, 110:234-239.

49. Sokolenko A, Lerbs-Mache S, Altschmied L, Herrmann RG: Clp protease complexes and their diversity in chloroplasts. Planta 1998, 207(2):286-295.

50. Halperin T, Zheng B, Itzhaki H, Clarke AK, Adam Z: Plant mitochondria contain proteolytic and regulatory subunits of the ATP-dependent Clp protease. Plant Molecular Biology 2001, 45(4):461-468.

51. Sjogren LL, MacDonald TM, Sutinen S, Clarke AK: Inactivation of the clpC1 gene encoding a chloroplast Hsp100 molecular chaperone causes growth retardation, leaf chlorosis, lower photosynthetic activity, and a specific reduction in photosystem content. Plant Physiol 2004 136(4):4114-4126.

52. Andersson Fl, Blakytny R, Kirstein J, Turgay K, Bukau B, Mogk A, Clarke AK: Cyanobacterial ClpC/HSP100 protein displays intrinsic chaperone activity. The Journal of Biological Chemistry 2006, 281(9):5468-5475.

53. Kiyosue T, Yamaguchi-Shinozaki K, Shinozaki K: Characterization of cDNA for a dehydration-inducible gene that encodes a CLP A, B-like protein in Arabidopsis thaliana. Biochemical and Biophysical Research Communications 1993, 196(3):1214-1220.

54. Nakashima K, Kiyosue T, Yamaguchi-Shinozaki K, Shinozaki K: A nuclear gene, erd1, encoding a chloroplast-targeted Clp protease regulatory subunit homolog is not only induced by water stress but also developmentally up-regulated during senescence in Arabidopsis thaliana. Plant J 1997, 12(4):851-861.

55. Lohman K, Gan S, John N, Amasino RM: Molecular analysis of natural leaf senesence in Arabidopsis thaliana. Physiologia Plantarum 1994, 92:322-328.

56. Weaver LM, Froehlich JE, Amasino RM: Chloroplast-targeted ERD1 protein declines but its mRNA increases during senescence in Arabidopsis. Arabidopsis 1999, 119(4):1209-1216.

57. Waters ER, Aevermann BD, Sanders-Reed Z: Comparative analysis of the small heat shock proteins in three angiosperm genomes identifies new subfamilies and reveals diverse evolutionary patterns. Cell Stress Chaperones 2008, 13(2):127-142.

58. Zhang Y: I-TASSER server for protein 3D structure prediction. BMC Bioinformatics 2008, 9:40

59. Kim YI, Levchenko I, Fraczkowska K, Woodruff RV, Sauer RT, Baker TA: Molecular determinants of complex formation between $\mathrm{Clp} / \mathrm{Hsp} 100$ ATPases and the ClpP peptidase. Nature Structural Biology 2001, 8(3):230-233.

60. Zimmermann P, Hirsch-Hoffmann M, Hennig L, Gruissem W: GENEVESTIGATOR. Arabidopsis microarray database and analysis toolbox. Plant Physiol 2004, 136(1):2621-2632.

61. Pelzmann A, Ferner M, Gnida M, Meyer-Klaucke W, Maisel T, Meyer O: The CoxD protein of Oligotropha carboxidovorans is a predicted AAA+ ATPase chaperone involved in the biogenesis of the CO dehydrogenase [CuSMoO2] cluster. Oligotropha carboxidovorans 2009, 284(14):9578-9586.

62. Hicks-Berger C, Sokolchik I, Kim C, Morre DJ: A plasma membraneassociated AAA-ATPase from Glycine max. Biofactors 2006, 28(2):135-149.

63. Vigh L, Nakamoto H, Landry J, Gomez-Munoz A, Harwood JL, Horvath I: Membrane regulation of the stress response from prokaryotic models to mammalian cells. Annals of the New York Academy of Sciences 2007, 1113:40-51.

64. Weibezahn J, Bukau B, Mogk A: Unscrambling an egg: protein disaggregation by $\mathrm{AAA}^{+}$proteins. Microbial Cell Factories 2004, 3:1

65. Zou J, Liu A, Chen X, Zhou X, Gao G, Wang W, Zhang X: Expression analysis of nine rice heat shock protein genes under abiotic stresses and ABA treatment. Journal of Plant Physiology 2009, 166(8):851-861.

66. Wu X, Shiroto $Y$, Kishitani S, Ito $Y$, Toriyama K: Enhanced heat and drought tolerance in transgenic rice seedlings overexpressing OsWRKY11 under the control of HSP101 promoter. Plant Cell Reports 2009, 28(1):21-30.

67. Yazaki J, Kishimoto N, Nagata Y, Ishikawa M, Fujii F, Hashimoto A, Shimbo K, Shimatani Z, Kojima K, Suzuki K, et al: Genomics approach to abscisic acidand gibberellin-responsive genes in rice. DNA Res 2003, 10(6):249-261.

68. Shen GA, Pang YZ, Lin CF, Wei C, Qian XY, Jiang LZ, Du XL, Li KG, Attia K, Yang JS: Cloning and characterization of a novel Hsp100/Clp gene (osClpD) from Oryza sativa. DNA Seg 2003, 14(4):285-293. 
69. Sanchez Y, Lindquist SL: HSP104 required for induced thermotolerance. Science 1990, 248(4959):1112-1115.

70. Lee YR, Nagao RT, Key JL: A soybean 101-kD heat shock protein complements a yeast HSP104 deletion mutant in acquiring thermotolerance. Plant Cell 1994, 6(12):1889-1897.

71. Schmitt $M$, Neupert $W$, Langer T: The molecular chaperone Hsp78 confers compartment-specific thermotolerance to mitochondria. The Journal of Cell Biology 1996, 134(6):1375-1386.

72. Tessarz P, Mogk A, Bukau B: Substrate threading through the central pore of the $\mathrm{Hsp} 104$ chaperone as a common mechanism for protein disaggregation and prion propagation. Molecular Microbiology 2008, 68(1):87-97.

73. Chomczynski P, Sacchi N: Single-step method of RNA isolation by acid guanidinium thiocyanate-phenol-chloroform extraction. Anal Biochem 1987, 162(1):156-159.

74. Thompson JD, Gibson TJ, Plewniak F, Jeanmougin F, Higgins DG: The CLUSTAL_X windows interface: flexible strategies for multiple sequence alignment aided by quality analysis tools. Nucleic Acids Research 1997, 25(24):4876-4882.

75. Saitou N, Nei M: The neighbor-joining method: a new method for reconstructing phylogenetic trees. Molecular Biology and Evolution 1987, 4(4):406-425.

76. Page R: TreeView: an application to display phylogenetic trees on personal computers. Computer Applications in the Biosciences 1996, 12:357-358.

77. von Arnim AG, Deng XW, Stacey MG: Cloning vectors for the expression of green fluorescent protein fusion proteins in transgenic plants. Gene 1998, 221(1):35-43.

78. Singh A, Sahi C, Grover A: Chymotrypsin protease inhibitor gene family in rice: Genomic organization and evidence for the presence of a bidirectional promoter shared between two chymotrypsin protease inhibitor genes. Gene 2009, 428(1-2):9-19.

79. Nigam N, Singh A, Sahi C, Chandramouli A, Grover A: SUMO-conjugating enzyme (Sce) and FK506-binding protein (FKBP) encoding rice (Oryza sativa L.) genes: genome-wide analysis, expression studies and evidence for their involvement in abiotic stress response. Mol Genet Genomics 2008, 279(4):371-383

doi:10.1186/1471-2164-11-95

Cite this article as: Singh et al:: Genome-wide analysis of rice ClpB/ HSP100, ClpC and ClpD genes. BMC Genomics 2010 11:95.

\section{Submit your next manuscript to BioMed Central and take full advantage of:}

- Convenient online submission

- Thorough peer review

- No space constraints or color figure charges

- Immediate publication on acceptance

- Inclusion in PubMed, CAS, Scopus and Google Scholar

- Research which is freely available for redistribution

Submit your manuscript at www.biomedcentral.com/submit 